\title{
Doctors accepting flu vaccination is the sensible and responsible choice
}

\author{
Jake Dunning clinical research fellow ${ }^{1}$, Jonathan Nguyen-Van-Tam professor of health protection ${ }^{2}$, \\ Karl Nicholson clinical professor of infectious diseases ${ }^{3}$, Peter Openshaw professor of experimental \\ medicine and director ${ }^{1}$
}

${ }^{1}$ Centre for Respiratory Infection, National Heart and Lung Institute, Imperial College London, London, UK; ${ }^{2}$ Faculty of Medicine and Health Sciences, University of Nottingham, UK; ${ }^{3}$ Department of Infection, Immunity and Inflammation, University of Leicester, UK

Patel's jaunty and amusing article concludes with: "after all, how bad can man flu be?"1 The answer is that, for men and women, flu can be devastating and even lethal. This is especially true for sick and vulnerable patients. Patel misses the point: we should be vaccinated not only to keep us hard at work through those long winter days and nights, but also to prevent us getting flu and, despite feeling lousy, struggling in to work and infecting our patients. Doctors cannot rely on recollection of symptoms to know whether they have been infected or are protected against flu. $^{2}$

In our study of 1520 patients with flu in 75 different NHS hospitals during the 2009 pandemic, we identified 30 cases of probable hospital acquired infection. Of these, 26 had serious underlying illnesses. Only 12 were treated with appropriate antiviral drugs within 48 hours of onset, more than half needed escalated care, and eight died. ${ }^{3}$ Although we do not know how many were infected by hospital staff, these findings clearly support this autumn's campaign to boost our patchy record on healthcare worker vaccination.

The arguments are not only scientific but moral. We all know that a precept of medical ethics is "first, do no harm," and the General Medical Council clearly advises us to conduct ourselves in a manner that minimises the harm we do to those in our care. ${ }^{4}$ Patel is wrong to focus on his personal freedom, seeming to ignore the potential consequences of his choices on the health and survival of his patients.
Competing interests: JD has no interests to declare. JN-V-T has received funding to attend influenza related meetings, lecture and consultancy fees, and research funding from several influenza antiviral drug and vaccine manufacturers and is a former employee of SmithKline Beecham (now GlaxoSmithKline), Roche Products, and Sanofi-Pasteur MSD. KN has received $\mathrm{H} 5$ avian influenza vaccines from Novartis and H1N1 pandemic influenza vaccines from GlaxoSmithKline and Baxter to facilitate MRC and NIHR-funded trials. He has received consultancy fees from Novartis and GlaxoSmithKline and lecture fees from Baxter. $\mathrm{He}$ is a member of the influenza subgroup of the Department of Health joint committee on vaccination and immunisation. $\mathrm{PO}$ is a member of the European scientific working group on influenza (ESWI) and a member of the influenza subgroup of the Department of Health joint committee on vaccination and immunisation.

1 Patel K. Resisting the needle: why I won't have the flu jab. BMJ 2011;343:d6554. (17 October.)

2 Elder AG, O'Donnell B, McCruden EA, Symington IS, Carman WF. Incidence and recall of influenza in a cohort of Glasgow healthcare workers during the 1993-4 epidemic: results of serum testing and questionnaire. BMJ 1996;313:1241-2.

3 Enstone JE, Myles PR, Openshaw PJ, Gadd EM, Lim WS, Semple MG, et al. Nosocomial pandemic (H1N1) 2009, United Kingdom, 2009-2010. Emerg Infect Dis 2011;17:592-8.

4 General Medical Council. Good medical practice: health. 2006 (updated 2009). www.gmcuk.org/guidance/good_medical_practice/health.asp.

Cite this as: BMJ 2011;343:d7199

๑ BMJ Publishing Group Ltd 2011 